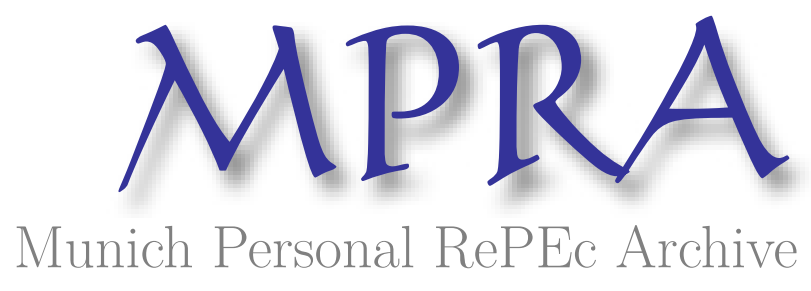

\title{
Behavioral Labor Economics
}

Berg, Nathan

2006

Online at https://mpra.ub.uni-muenchen.de/26366/

MPRA Paper No. 26366, posted 04 Nov 2010 09:18 UTC 
$<<$ CHAPTER 23 $>>$

$<<$ AB HEADS, REFERENCES $>>$

<<WORDS: 12,353; CH: 85,323>>

\section{Behavioral Labor Economics}

Nathan Berg

Behavioral economics has in recent decades emerged as a prominent set of methodological developments that have attracted considerable attention both within and outside the economics profession. The time is therefore auspicious to assess behavioral contributions to particular subfields of economics such as labor economics. With empirical validity among its chief objectives, one might guess that behavioral economics would have made its clearest mark in data-driven subfields such as labor economics. It has been more theoretical subfields, however, that have led much of the recent behavioral movement, drawing on laboratory data for its empirical basis as opposed to the large panels of field observations common in labor economics. Motivated in part by the question of why labor economics has been a relatively slow adopter of behavioral theory, this essay surveys a wide range of behavioral studies that address core labor issues. The objective of the survey is to construct a map of areas within labor economics in where behavioral methods have already produced new insights, in hopes that the existing literature (and the gaps therein) will suggest new directions for future applications of behavioral concepts. Comparison and contrast of neoclassical versus behavioral methods and the consequences of those methodological differences provide the map's relief, bringing high and 
low points of the current labor literature's coverage into sharper focus.

One finding of this survey worth pointing out at the outset is that, rather than two disjoint bodies of work, the relationship between behavioral and neoclassical economics appears to be that of superset and subset. Instead of rejecting neoclassical concepts such as self-interest, maximization, and equilibrium, behavioral economists' methodological agenda proves to be one of expansion and generalization. This suggests a possible explanation for why the influence of behavioral economics in labor economics has been less dramatic than in other subfields. It seems that neoclassical practitioners in labor economics have been unusually frank in exposing the empirical problems with standard labor market theory and unusually creative in considering the complexity of labor market decisions and their psychological dimensions.; Therefore, the gap between traditional and behavioral labor economics ies is less dramatic than in other subfields of economics. Thus, the survey aims to describe contrasts between behavioral and neoclassical approaches to labor economics while revealing how fuzzy the boundary separating the two actually is. Kaufman $(1989,1999)$ in his essays on the behavioral foundations of labor economics similarly argues that the behavioral approach is, in principle, an expansion upon rather than a departure from the psychological foundations of neoclassical economics. In practice, however, the behavioral/neoclassical distinction represents a real boundary. In spite of abundant evidence that psychological factors play a critical role in labor market decisions, Kaufman reports that only two papers in the Journal of Labor Economics from 1992 to 1997 adopted expanded or modified models of man that considered psychological processes (i.e., models that include decision-making elements other than narrow self-interest, maximization, and fixed preferences).

Regarding the fixity of preferences, Kaufman acknowledges the concern of Gary Becker 
that models that admit psychological complexity and preference change run the risk of overexplaining observed economic decision making. Kaufman illustrates his counterposition in favor of dynamic preferences with the much studied problem of explaining the reduction of annual work hours in the United States over the period 1900-1980. The neoclassical explanation for this pattern is that a large income effect in response to rising real wages resulted in increased consumption of leisure and fewer hours on the job. The fixed preference paradigm posits that the average worker in 1900 would have made the same labor/leisure choice as today's average worker if the real wage in 1900 had been what it is today. Since 1980, however, the trend has reversed. The real wage in the United States has continued to rise but annual hours on the job have increased. If the neoclassical story has trouble matching the facts, Kaufman asks, why not consider cultural, sociological, and psychological variables, including hypotheses that link observed patterns to systematic changes in preferences? Of course the validity of new explanations is not immediately obvious, and subjecting them to empirical and theoretical tests is an important part of the behavioral agenda. The point, however, is that in addition to falsifying existing theories there is a role in economic science for the synthesis of new ideas.

The collection of material reviewed below focuses broadly on behavioral studies that adopt models of man consistent with the recommendations in the Kaufman essays. The survey provides cause for optimism that attempted realism is worth its cost in terms of forgone theoretical parsimony. In fact, the price of realism is quite low when the next best alternative fails to deliver the predictive power positivists claim in favor of as-if theory. When the price is as low-as it is, for example, in the case of the falsified income-effect explanation of labor-supply trends in the United States - it is easy to predict that consumers of economic thought will increasingly buy behavioral in years to come. 
The survey is divided into sections covering worker effort, labor supply and income tax policy, heterogeneity in labor markets, reciprocity and trust, and finally labor contracts, unions, and the scheduling of work. The last section summarizes the resulting map of behavioral labor economics and suggests five priorities for future research.

\section{Effort}

It is common in neoclassical economics to assume that effort is constant, and therefore that the cost of employing a particular quantity of effective labor is linear in time spent on the job. The assumption that effort is impervious to physical weariness, opportunities to find work elsewhere, the wages of other workers, and even the absolute level of the worker's own real wage derives from an analogy based on physical capital. This analogy supports the constant-effort assumption by noticing, for instance, that a well-functioning meat grinder's capacity to transform inputs into outputs does not vary in its second versus ninth hour of use, with the machine's price, or with management's decisions about whether and for how much to rent other machines.

Were it easy to observe, monitor, and measure effort, we might expect firms to contract with workers for levels of effort in addition to quantities of labor hours. Alternatively, one might argue that the widespread practice of paying wages in exchange for time, with effort levels left unspecified, implies that approximation error resulting from the constant-effort assumption is minor relative to the costs of quantifying and contracting for effort. However, to Adam Smith, the variable nature of effort was important enough to write, "Where wages are high, accordingly, we shall always find the workmen more active, diligent, and expeditious, than where they are low" (quoted in Altman 1999a). Evidently Smith saw some psychological regularity underlying 
workers' supply of variable effort.

Arguing in favor of building richer psychological content into economic models, some have since wondered whether the economists of Smith's day understood human psychology better than economists do today (Gilad and Kaish 1986; Lewin and Strauss 1988; Schwartz 2002). The articles reviewed in this section are based on the premise that the constant-effort hypothesis is incomplete, and that by studying the determinants of variable effort, new insights into the real-world practices of firms and their employment of labor may emerge.

\section{Efficiency Wages, Psychology, and Unemployment}

The efficiency wage models of the 1980s reintroduced to mainstream economics the idea of an effort function that depends on real wages. This modification fit within an otherwise neoclassical framework of maximization and competition while producing involuntary unemployment as an equilibrium outcome. Motivated largely by the failure of neoclassical macroeconomic models to satisfactorily explain real wage rigidity in the United States and elsewhere, some economists turned to more complicated models of the psychology of work, models that implied variable levels of effort (Akerlof 1982; Shapiro and Stiglitz 1984).

Assuming that effort increases as a function of the real wage, with convex and then concave regions, there exists a unique point on the effort curve that maximizes effort per dollar of real wage. Under quite general conditions, profit maximization implies that firms choose that point, referred to as the efficiency wage. Thus, firms choose to pay the efficiency wage no matter what labor supply conditions are, and the wage gets stuck there, above the level that would otherwise clear the labor market. 
The basic efficiency wage model implies that, so long as the effort curve is fixed, the real wage paid by firms is absolutely rigid and does adjust downward during recessions or when there is excess labor supply. The reason that unemployed workers cannot bid the wage down is that firms, although they would be happier to pay less when hiring additional workers, anticipate higher costs associated with shirking, the result of reduced effort in response to a lower wage. Because the efficiency wage already optimally trades off the savings of shirking costs against additional cash wage outlays, agreeing to low-wage offers by unemployed workers is unattractive to firms: the costs of increased shirking outweigh the savings on wages.

The psychology underlying effort curves reflects assumptions about worker motivation and the need for there to be a noticeable gap between workers' satisfaction with their jobs and being unemployed. Otherwise the threat of dismissal is ineffective in eliciting effort, according to efficiency wage theory. At lower wages, workers are nearly indifferent between working and being unemployed, and therefore have little incentive to work hard. Workers may also feel the wage is unfair if it is perceived as being low relative to wage expectations, providing a rationale for firms to fire workers instead of lowering wages, in an effort to preserve high levels of effort among the employed. In contrast, at higher wages, the psychology of gift exchange becomes relevant, as workers supply additional effort to reciprocate for the employer's willingness to pay more than the minimum possible.

Critics have pointed to flaws in the efficiency wage theory having to do with its incomplete account of effort and firms' strategies in eliciting the desired level of it. Carlin (1989) observes that many firms permit certain forms of shirking without firing workers. Carlin points out that firing can be costly and that the degree of shirking varies across firms, variation that is not adequately explained by efficiency wage theory. In his game theoretic model of effort supply 
and incentive design on the part of firms, asymmetric information is required to deter shirking, implying that workers' uncertainty about the consequences of shirking may be an important part of what motivates them.

Other critics suggest that maximizing effort per dollar of wages may not be a wise objective for firms. Assuming workers derive positive utility from shirking, permissive managerial stances can serve as a cheaper alternative to cash compensation. Another reason why firms may find it in their interest to allow workers the discretion to shirk is that doing so provides the firm with valuable information. Observing who among workers shirks and who voluntarily exhibits discipline can help guide promotion decisions, especially in identifying prospects for future managerial positions (Ireland 1989).

Apart from the theoretical possibility that positive levels of shirking serve a useful economic function, analysts with direct evidence of worker-firm relations and the wage-setting process raise doubts as to whether shirking is an important consideration in the first place. In U.S. and Swedish samples of managers and labor negotiators, shirking rarely surfaces as a major concern (Bewley 1999; Agell and Lundborg 2003). Instead, these studies point to factors such as workplace morale and the psychological dynamics of discouragement and unemployment as the relevant considerations for those directly responsible for setting wages.

Research with a more explicitly psychological bent has uncovered interesting patterns among psychometric measures of workers' mental states and objective measures of productivity. Such work has led to more intricate theories of unemployment in which psychological wellbeing and joblessness are endogenously determined (Darity and Goldsmith 1996). The basic idea is that unemployment hurts workers' productivity. Lower aggregate productivity, in turn, depresses labor demand, which, in a self-reinforcing cycle, begets further unemployment. The 
process by which unemployment damages a worker's psychological well-being can be differentiated by psychometric criteria into categories such as self-esteem, learned helplessness, loss of practice and skills, and depression (Feather 1990; Goldsmith and Darity 1992; Korpi 1997).

The dynamics of employment and psychological well-being imply that path dependence and multiple equilibria are important to consider. For example, when a severe spell of unemployment leads to psychological depression, from that point on, future bouts of psychological depression are more likely, even if future economic downturns are less severe, because the availability of depressive episodes in the brain's memory heightens susceptibility to its recurrence. Thus, steady-state levels of unemployment and psychological distress are tied to history, and the contrast between low-employment/high-mental-health equilibria and inferior equilibria featuring high unemployment is stark.

The Darity and Goldsmith perspective advocates that labor economics rely more on quantitative attitude measures. Their emphasis on psychological health brings out implications that contrast sharply with the assumptions of efficiency wage theory. In efficiency wage theory, the threat of dismissal is a primary motivator that leads employees to supply high levels of effort. (Recall that, according to efficiency wage theory, firms are hypothesized to set wages above the market-clearing level so that the opportunity cost of job loss is high enough to induce high effort.) In contrast, Darity and Goldsmith's work cautions that the threat of unemployment is itself a stressful event, one that can potentially reduce productivity. While acknowledging that fears of job loss may motivate some workers to provide additional effort, Darity and Goldsmith emphasize instead that on-the-job effort can be compromised when workers spend effort seeking alternative employment opportunities, experience "survivor guilt" following a round of layoffs, 
or suffer from poor concentration as a result of the emotional toll of job insecurity.

Another implication of the hypothesis that unemployment harms worker productivity is that employers may rationally use a worker's unemployment history as a basis for predicting productivity and making hiring decisions. This points to yet another theoretical cause of hysterisis. A bout of unemployment shrinks the pool of workers with unbroken employment histories, and therefore shrinks the pool of workers regarded as having desirable work histories. Thus, unemployment itself reduces the supply of desirable workers, reducing the number of hires, leading to another round of increased unemployment. The idea that employers take cues from workers' employment histories also implies the existence of multiple equilibria. Highemployment, high-output steady states are possible, just as low-employment, low-output steady states are. Thus, there is scope for policy to intervene and guide the economy away from less desirable paths. Path dependence and the multiplicity of equilibria, in many economists' eyes, provide a rationale for policies aimed at reducing unemployment and maintaining the psychological health of the temporarily unemployed.

Gender asymmetries are another consideration in analyzing the gap between wages and levels of effort. Those who study the well-documented male marriage premium, widely reported in the empirical labor literature, suggest that the anomalous premium may actually serve to compensate spouses who supply productivity-enhancing inputs that improve the husband's performance at work (Grossbard-Shechtman 1986). Another behavioral hypothesis relating to marriage is that firms value certain "virtues" that they believe are positively correlated with marital status (Grossbard-Shechtman 1988). Students of gender issues in the workplace have, however, found surprising uniformity across male and female workers in survey-based measures of workplace stress and other attitudinal variables (Allen and Fry 1987). If wage asymmetries 
involving gender and marriage could be explained in terms of productivity, then one might expect to see these asymmetries reflected in survey data measuring stress, intensity of work, and attitudes toward employers.

The economics of effort literature has also investigated the concept of stress and the possibility that excessive effort causes problems for workers and their employers. Although high-stakes incentive structures can temporarily boost output by eliciting "workaholic" behavior from employees, such structures frequently prove to be unsustainable, ending in costly burnouts and highly uncooperative worker dispositions (Camerer 1998). Although there is abundant evidence that increased rewards do indeed elicit greater effort, the efficacy of effort becomes problematic when effort is taken to excess, as when athletes "overthink" their actions and choke under pressure, or when performance-based rewards, such as bonuses or sales competitions, wind up harming morale because they are perceived as unfair (Wiesenfeld and Brockner 1998).

Employing an otherwise neoclassical framework, Kantarelis (forthcoming) shows that maximizing profit and maximizing output are conflicting goals. The profit-maximizing level of workplace stress is, as one would expect, less than the level that maximizes output. Screening for stress and labeling it as an affliction can itself cause stress, leading to higher levels of absenteeism (Westman and Gafni 1988).

Another question regarding the economic analysis of stress is whether it should be explicitly included in cost-benefit studies of project proposals in both private industry and the public sphere. Although cost-benefit studies rarely attempt to account for psychic costs of stress and the resulting dollar costs arising from its physiological manifestations, Schechter (1988) makes the case that psychic costs of stress and anxiety should be explicitly figured into studies of certain environmental impact studies. Although this debate is relatively recent, and far from 
being resolved, there is at least some consensus on the characteristics of risk that consumers and workers find most distressing: those that are involuntary, are uncontrollable, or have delayed consequences (Pieters and Verplanken 1988).

\section{X-Efficiency}

Effort variability and the interdependency of workers' effort supply are central components of Harvey Leibenstein's theory of X-efficiency (Leibenstein 1986; Altman 1992). Because workers dislike being monitored by managers and tend to respond to the distrust it signals by shirking (i.e., supplying a lower level of effort along any dimension over which the worker enjoys discretion), there is scope for a mutually beneficial exchange: reduced monitoring in return for higher voluntary levels of effort. According to X-efficiency theory, as monitoring and sanctions against low-effort behavior increase, two opposing results follow. First, the minimum feasible level of effort (chosen by workers with antagonistic feelings toward management or other reasons to shirk) rises because the threshold at which monitors intervene and sanctions go into effect is set to be more sensitive to shirking. All else equal, this pushes workers to supply increased levels of effort. The second result, which pushes worker behavior in the opposite direction, is a decrease in voluntary effort chosen by workers from within their discretionary bounds. This is a reciprocal response to managers who signal distrust by stepping up monitoring, delegating less, and restricting the range of discretion in employee hands.

According to Leibenstein, most workers do not bump up against workplace sanctions frequently enough to be fully aware of what they are or where the thresholds lie that trigger disciplinary responses from management. Another aspect of Leibenstein's framework is the 
general idea of inertia within bounds combined with discrete responses at the boundaries. In terms of worker behavior, this means there is typically a wide range of effort levels over which no response from management is forthcoming - no change in wage, no disciplinary response, no feedback at all. Thus, factors such as the attitudes of other workers and the degree to which participatory modes of decision making are implemented as workplace norms determine whether high or low levels of effort are chosen from within workers' discretionary bounds.

Leibenstein and other analysts of X-efficiency emphasize the importance of interaction between patterns of production and worker morale, suggesting that conventional measures of economic efficiency fail to identify unrealized opportunities for both higher wages and increased output per wage dollar. Whenever a given level of effort at a given level of monitoring could be supplied voluntarily under an alternative managerial policy, the firm has not attained Xefficiency. In effect, there is a prisoner's dilemma in which high monitoring and low effort are the dominant strategies. According to Leibenstein, the individually rational yet collectively unwise Nash equilibrium can be improved upon by means of consensual procedures and effort conventions that attain high-effort, high-wage/good-work-condition outcomes.

Although Leibenstein tied X-inefficiency to market imperfections, which allow firms with suboptimal management to survive, subsequent research has shown that even under perfect competition, X-efficiency is not guaranteed so long as effort is a function of the real wage (Altman 1996). That competition fails to ensure X-efficiency poses an important problem for studies of labor market discrimination. Given X-inefficiency, lower pay that was caused by discriminatory animus will at some point lead to lower productivity. At that point, disentangling discrimination from productivity differentials becomes more complicated.

Neoclassical discrimination studies, based on the premise that the expected wage function 
in a discrimination-free environment should depend exclusively on factors tied to worker productivity, may fail to detect discriminatory outcomes (Altman 1995). The discriminatedagainst worker who responds to an unfairly low wage by withholding effort appears to be paid fairly when viewed through the neoclassical lens.

Frantz (1986) provides empirical evidence of widespread X-inefficiency. He describes a psychological basis in terms of id and ego for the quadratic-shaped relationship between managerial pressure and effort/performance. Sometimes referred to as the Yerkes-Dodson law in psychology, the arc-shaped relationship between pressure and performance is a key implication of X-efficiency theory.

Organizational theory takes on added importance within the X-efficiency framework. If particular patterns of work and managerial techniques elicit higher effort with lower monitoring costs, then one would hope for a prescriptive theory explaining how to organize production and create high-effort X-efficient firms. Empirical studies of work structure and managerial practices reveal a surprising degree of variation, even among longtime rivals in competitive industries (Altman 2002). This suggests that competition does not necessarily produce convergence across firms in the structure and style of work. Either there exist many profit-maximizing management strategies or X-inefficiency is a common problem that is difficult for owners and managers of firms to solve.

A number of essays have been published with prescriptive recommendations aimed at achieving X-efficiency. Recommendations have focused on areas such as effort-augmenting organizational capital (Tomer 1986), recruitment and job redesign (Filer 1986), the interface between workers and the acquisition of new physical capital (Evangelista 1996), and techniques for improving relations among workers (Frantz and Green 1982). Policies intended to improve 
working conditions have also been analyzed in connection with X-efficiency, as a means for enabling firms to switch away from low-effort/low-wage equilibria to superior high-wage/higheffort outcomes. Such policies include minimum wage legislation (Altman 1992), restrictions on child labor (Altman 2001a), and expanded negotiating rights for organized labor (Altman 2000). The potential for these interventions to help the economy achieve a superior equilibrium follows from the multiple-equilibria implication of X-efficiency theory. In contrast, the singleequilibrium neoclassical approach almost always concludes that these same policies are inefficient, at least by the Pareto criterion.

\section{Relative Position}

One of the most widely discussed issues at the frontier of labor economics is social hierarchy and the role that coworkers' incomes play in determining a worker's satisfaction with his or her own income. More and more economists accept the idea, for example, that workers typically would prefer to earn $\$ 90,000$ at a firm where the average worker earns $\$ 50,000$ over a salary of $\$ 100,000$ at a firm where the average is $\$ 200,000$. Frank (1987) refers to goods such as labor income, whose relative quantities, in addition to absolute levels, affect utility, as positional goods. By specifying preferences with utility representations that depend on the consumption levels of others, as well as one's own consumption, Frank's generalization of the neoclassical utility framework formalizes an idea found in Duesenberry (1949), Veblen (1899), and Adam Smith's Theory of Moral Sentiments: that social hierarchy is a crucial element that any general theory of choice must address.

The notion of other-regarding preferences leading individuals to seek relative position in 
hierarchical systems can be justified in evolutionary terms, as a hardwired feature of human decision making (Gintis 2000), or as the result of competitive pressures in present-day decisionmaking contexts such as the mutual fund industry (Berg and Lien 2003). Complementing such theoretical arguments that seek to provide a rationale for the prevalence of other-regarding preferences, the psychological literature on motivation provides abundant experimental evidence in support of the idea that relative consumption can be just as important as absolute consumption (Baxter 1988). Lazear's (1995) Personnel Economics, while critical of Frank's theory of positional goods, develops innovative arguments more closely rooted in neoclassical theories of asymmetric information and commitment problems in strategic settings, ultimately arriving at similar conclusions: that economics must take account of emotions and relative comparisons in order to understand many important features of contemporary labor markets.

Clearly, more empirical detail is needed to disentangle the many determinants of effort. Extant empirical work in this area verifies that effort and productivity are indeed highly variable, even over short stretches of time when wages are fixed (Boddy, Frantz, and Poe-Tierney 1986; Filer 1987). It is also well established that quantitative attitude measures help explain variation in effort (Norsworthy and Zabala 1990) and that effort supply rests on a deep sociological foundation (Akerlof and Yellen 1990). Innovation in the measurement and empirical analysis of effort will almost surely continue as a focus in behavioral labor economics.

\section{Labor Supply, Incentives, and Taxes}

\section{Behavioral Analyses of Labor Supply}


One of the most famous of recent labor-supply findings concerns New York City cab drivers (Camerer et al. 1997), who reportedly work fewer hours on days when customers are plentiful and longer when paying customers are difficult to find. This pattern of behavior implies that cabbies' daily supply of hours is negatively correlated with their wage, the return on an hour spent in the cab. Because cab drivers choose their own hours, and day-to-day wages are transitory rather than permanent (the result of factors such as weather, the scheduling of conventions, and subway breakdowns), the cab driver data appear to offer a clean test of whether intertemporal substitution decisions adhere to standard life-cycle theory.

The standard theory predicts that as long as a worker's time horizon is longer than a day, workers should work longer on high-wage days and rest when the cash wages forgone are low, that is, on slow days. New York City cab drivers' behavior is inconsistent with that prediction. Instead, their behavior appears to be consistent with a one-day time horizon and a simple income-targeting rule: work until the daily earnings target is reached and then stop. Subsequent work has questioned the income-targeting interpretation of the cab driver data, raising the possibility that other factors better account for the negative wage-hours correlation, including errors in reported hours or physiological constraints (Fehr and Goette 2002; Farber 2003). Nevertheless, strong psychological evidence in favor of reference points and the bracketing of decision problems into smaller units (e.g., focusing on daily rather than weekly or lifetime earnings) makes plausible the income-targeting hypothesis and helps account for its extensive track record in economics (Sharir 1976; Altman 2001b).

Another prominent instance of economists drawing on experimental evidence rooted in the psychology literature to put forth an alternative model of decision making is the concept of loss aversion. Loss aversion is a preference specification in which a particular reference-point 
level of consumption plays a dominant role. Relative to the reference point, a one-unit reduction in consumption generates loss of utility with a magnitude that exceeds the utility gain from a one-unit increase. Thus, the utility function, an increasing function of consumption as in standard utility models, is kinked, and its slope is flatter to the right of the kink. In addition, loss-aversion theory frequently assumes risk-loving behavior over losses, implying convexity to the left of the kink, and risk aversion, or concavity, to the right. The loss-aversion utility specification is based on the observation that decision makers who exhibit risk aversion over positive outcomes often prefer to gamble over negative outcomes rather than accept a certain loss.

Loss aversion is used to account for a wide variety of apparent anomalies in economics, and Dunn (1996) applies it to explain the puzzling observation that many workers choose to work just until overtime pay rates are about to start, quitting for the day just when wage rates jump to higher overtime levels. This behavior appears to be inconsistent with standard neoclassical models of labor supply, which imply that workers work up to the point where the wage just offsets the marginal disutility of the last hour or minute of work. Assuming that disutility of work (frequently assumed to equal the utility of leisure) is twice differentiable, then the marginal disutility of work should increase smoothly and no discrete jumps in the worker's psychic costs of work are possible.

Under these assumptions, the observed stopping behavior does not make sense. Because the worker agrees to work the last hour at the lower regular wage, we infer that the disutility of the eighth hour is less than the regular wage. When the worker quits for the day instead of working one overtime hour, we infer that the disutility of the ninth hour overwhelms even the larger overtime wage in magnitude. This implies a dramatic jump in the disutility of work, whereby the psychic cost of the ninth hour is dramatically higher than that of the eighth. But this 
is inconsistent with the smoothness assumptions already made about the utility function.

Thus, with neoclassical smoothness assumptions in place, the observed behavior is not rational. However, assuming that the relevant reference point is the eight-hour workday, then the kinked utility function implied by loss-averse preferences is consistent with observation. Accepting the regular wage to work the eighth hour while refusing a higher overtime wage for the ninth hour is consistent because the utility-of-consumption function is relatively flat to the right of the eight-hour-day reference-point level of consumption, effectively discounting the value of additional consumption financed with the higher overtime wage.

Animal studies have explored a number of behavioral hypotheses about labor supply and the theory of choice (Kagel, Battalio, and Green 1995), discovering remarkable consistency with reported findings in human populations. Income-compensated variations in relative prices demonstrate negative substitution effects. And in terms of labor supply, strong income effects give rise to rapidly backward-bending labor supply curves. Violations of the expected utility axioms have been reported, as well as evidence consistent with loss-averse preferences.

As alluded to in the introduction, behavioral economists looking at labor supply trends through time have identified problems with neoclassical explanations of fluctuations in the level of employment. Standard explanations for such trends typically rely on factors such as population size, the real wage, human capital, and fertility trends. Behavioral research has expanded upon such analyses by considering macro-level cultural trends and the possibility of preference change. For example, Altman (1999b) attributes the shortening of the workweek in Canada from 1880 to 1930 to shifting preferences. And Romme (1990), analyzing increasing trends in the labor supply of females in Holland, explicitly rejects the connection between real wage and labor supply in favor of cultural variables and dynamic preferences. 
Another segment of the labor supply literature working to extend neoclassical models to include a wider set of behavioral variables is that focused on the problem of estimating wage premiums associated with risky jobs. One goal related to this problem is to decompose the wages of occupations such as firefighters, pilots, and waste disposal personnel into separate terms reflecting human capital and compensation for bearing risk. Such studies require a delicate quantification of risks, however, which has forced economists to conceive of risk in greater detail than the traditional risk-is-variance approach would suggest. Whether risks are voluntary, controllable, or delayed registers strongly with most workers' preferences. Saliency also plays a role, wherein easy-to-conjure or highly vivid risks (such as airplane crashes) are overweighted relative to the prescriptions of expected utility theory. Small risks that may seem less dramatic (such as skin cancer due to sun exposure) also appear to be systematically underweighted. Reber, Wallin, and Chhokar (1984) attempt to apply these results and produce behaviorally informed normative guidelines aimed at helping modify workplace behavior and improve safety.

Although many interesting empirical estimates have emerged regarding workplace risks and compensation, there is considerable pessimism about their reliability because of numerous auxiliary assumptions that are required (Dickens 1990). Hedonic wage regressions that use human capital controls to absorb variation due to nonrisk factors rest on the assumption that wage data are observed in states of competitive equilibrium and that the risk factors are correctly (i.e., rationally) priced. Lack of competition in labor markets, together with the difficulty workers face in learning about possible negative outcomes and their rare-event distributions, make it unlikely that job-risk coefficients from wage regressions have the desired interpretation, as willingness-to-pay for risk avoidance. 


\section{Entrepreneurship and Innovation}

Perceptions of and attitudes toward risk are fundamental to understanding variation in rates of innovation and business creation. Thus, behavioral economics has a comparative advantage in studying entrepreneurship. The study of innovation and entrepreneurship from a behavioral perspective has much in common with the economic subfield of Austrian-school analysis and the intellectual tradition of Schumpeter and Hayek (Gilad, Kaish, and Ronen 1988). Shared priorities, aimed at relaxing the neoclassical methodological norms of perfect rationality and equilibrium, bring together a remarkably wide range of political orientations under the umbrella of behavioral economics (Berg 2003). It should not be surprising, however, that ideology and political orientation recede as secondary concerns in behavioral economics, which touts empiricism as its unifying theme.

The Schumpeterian tradition asserts that economics can produce analytical insights without the assumptions of maximization and equilibrium (Helmstadter and Perlman 1996), focusing instead on expectation formation and the creative process underlying the synthesis of new ideas, products, and firms. This Austrian-style behavioral literature analyzes a number of interesting policy debates that hinge on the question of economic rewards, the disincentivizing effects of redistribution using income taxes, and the social disruptiveness of technological innovation. Shen's (1996) Schumpeterian simulation study illustrates these points, defying ideological tradition by finding that a progressive income tax, which discourages entrepreneurial activity to a certain degree by lowering the return on risk taking, may be socially optimal.

The study of innovation in behavioral economics overlaps with the analysis of how firms are managed and the search for organizational schemes that nurture creativity, discoveries, and 
economic growth. In this spirit, Schwartz (1987), based on in-depth interviews, provides prescriptive guidelines for managers to help reduce inefficiency resulting from decision-making pitfalls such as failing to gather technological information, unreasonable resistance to change, nominal/real interest rate confusion, overreliance on outsourcing, and unfounded assumptions about quality-price correlation when purchasing inputs. Drawing on multiple methodological traditions, Langowitz (1991) constructs a complementary list of organizational suggestions focused on improving interactions between firms and their workers. And O'Higgins (1988) documents the importance of matching managers to particular kinds of tasks according to their relative strengths in entrepreneurial thinking versus cost-minimizing analysis.

\section{Taxes and Income Redistribution}

Income tax policy is a controversial topic, in part because difficult-to-verify behavioral assumptions deeply affect the conclusions and policy implications of competing theoretical models, especially models of labor supply and savings decisions. The relationship between labor supply and marginal income tax rates is crucial in analyzing how income taxes affect economic output. In the tax policy literature, the label "behavioral" is often used to signify simply that a particular model allows for labor supply adjustment in response to changes in tax rates (Duncan and Weeks 1997).

As far as the empirical record goes, correlations and structural estimates of labor supply elasticities with respect to income tax rates are notably small. According to Krueger (2003), the best estimates from the vast labor supply literature imply that a tax cut that raises take-home income by 10 percent would expand labor supply by only 1 percent among men and 3 percent 
among women. Such small magnitudes rule out (Hausman and Poterba 1987) the claims by some that tax cuts would pay for themselves, at least through the labor supply channel.

Behavioral tax analyses tend to bring in additional empirical detail often suppressed in representative-consumer neoclassical studies of tax policy and taxpayer behavior. Apps and Rees (1996) find that introducing household production and intrafamily welfare distributions can reverse the policy implications of empirical income tax studies. Thus, the requirements that members of households have identical objectives and that consumption is distributed evenly within the household are not innocent assumptions.

Another assumption that substantively influences conclusions about optimal tax and income-redistribution policies concerns whether workers' labor supply responses take the form of adjustment along the extensive (entering the labor force or not) or intensive (adjusting effort or hours of work) margin. When labor force participation is the dominant mode of response, the optimal policy, according to Saez (2002), is one that provides a low level of guaranteed income and negative income tax rates over low income levels, as with the earned income tax credit. When effort/hours adjustment is more pronounced, however, the preferred policy provides a larger minimum level of income and a more rapid phasing out of transfers as income increases.

Another tax-related topic of interest to behavioral economics is charitable giving and the interaction of altruistic sentiments and tax policy. Although some policy analysts have expressed optimism that tax incentives might be used to stimulate private charitable giving and reduce government transfers without reducing overall support for the needy, Barrett, McGuirk, and Steinberg (1997) estimate that reducing taxes on charitable giving by $\$ 1$ raises charitable giving by only 40 cents.

Another behavioral question about income redistribution concerns non-labor-supply 
responses to income maintenance programs. In an overview of reported outcomes from income maintenance experiments in the United States, Hanushek (1986) provides several encouraging observations. He finds that children of transfer recipients spend less time at work and more time studying. Also, based on comparisons of average consumption before and after transfer programs were begun, it does not appear that recipient families binge on extra consumption, as some feared they might.

\section{Worker Heterogeneity}

Part of what makes behavioral economics stand apart from the neoclassical approach is its interest in describing the particularity of special groups. Deviations from the average become the object of study rather than a nuisance to be dispensed with en route to the application of representative agent theory. Thus, descriptive studies detailing heterogeneity and its consequences enjoy a well-established home in the behavioral literature. In contemplating the underlying causes of heterogeneity, it is interesting to consider the tremendous variation in preferences reported in animal studies, e.g., taste for income, or risk aversion - despite strict laboratory controls over gene pools and environmental conditions (Kagel, Battalio, and Green 1995).

Descriptive labor studies are common to behavioral economics, sociology, and other disciplines within the social sciences. Beyond common demographic categories such as race, gender, age, and geography, the behavioral labor literature provides comparative descriptions of other kinds of special groups as well, sometimes based on distinct types of preferences, disease (Kahn 1998), or job type (Sorenson 1990). Gender is an especially important and frequently 
analyzed dimension of heterogeneity.

\section{Gender}

There is a strong link between behavioral economists' analyses of gender and neoclassical studies of household behavior, both of which deal with the problem of aggregating the choices of household members and the possibility of conflicting interests within households. Stiglitz's (1988) analysis of productivity differences and household decision making demonstrates that gender can be brought into the neoclassical framework while maintaining assumptions such as negative marginal utility of effort, constant preferences, and the fixity of cultural and sociological norms. Phipps and Burton (1995), on the other hand, critique the limitations of neoclassical household analysis, preferring instead to quantify social/institutional variables that describe cross-country heterogeneity, checking observed correlations against reduced-form implications from more complex theoretical models.

Empirical research into gender heterogeneity points to the importance of jointly specifying labor supply and fertility decisions (Di Tommaso and Weeks 2000) in econometric studies of female labor supply. Another complication is that couples do not make labor supply decisions independently. One component of the joint labor supply problem is scheduling work so that leisure hours overlap, which imposes constraints on the jobs and hours couples choose (Chenu and Robinson 2002). Case studies of executives and other relatively successful workers at a particular rank and level of income reveal that female career trajectories into leadership roles are noticeably different, in general requiring more time, on-the-job experience, and family sacrifices from women (Martin and Morgan 1995). 
Unequal distribution of consumption within the household gives rise to another kind of gender asymmetry, one that can make real household income a poor measure of household wellbeing (Altman and Lamontagne 2003). Women in households with highly unequal distributions may be relatively deprived, despite belonging to a well-off household. Thus, without knowledge of within-household distributions of resources, measurement of well-being requires consumption data disaggregated from the household down to the individual level.

\section{Explaining Heterogeneity}

Beyond describing particular segments of the labor market and their special characteristics, behavioral economics is also concerned with the underlying causes of heterogeneity. Henrich and colleagues (2001) conduct ultimatum-game experiments in fifteen small-scale societies from twelve different countries, uncovering tremendous variety in the degree of reciprocal behavior. Rejecting the self-interest/zero-reciprocity model in all groups studied, and noting that individual demographic variables fail to explain variation in individual levels of reciprocity, the study provides an alternative environmental explanation. Using quantitative measures of the degree to which different groups' techniques of production and patterns of exchange require interaction and cooperation, the authors link group-level environmental variables to variation in reciprocity. This widely discussed finding implies that the rational self actor model should be enlarged to include a moderate degree of reciprocity and that preferences are systematically shaped by economic environments rather than exogenously determined.

Other single-population studies have, in the absence of good data on variation of the environment, found that demographic variables such as age, earnings, race, and gender do help 
predict reciprocity, as measured by proposed divisions of the pie and rates of rejection in ultimatum game experiments (Eckel and Grossman 2001). Thus, the role of individual demographic characteristics in explaining different propensities to reciprocate remains an open question. The fascinating issue of explaining preferences in terms of economic environments promises to be an area worthy of more investigation, despite the high costs of cross-cultural studies such as that of Henrich and colleagues (2001) and the requirement of anthropological expertise.

A variety of other forms of heterogeneity have been studied using conventional regression analysis. For example, workers in more competitive industries report higher levels of happiness, possibly suggesting that competitive pressures lead firms to improve working conditions (Tiemann and Veglahn 1979). In an efficiency study of farmers in India, those who are older, own large or geographically fragmented land holdings, or have subsistence needs in addition to raising cash crops appear to be less efficient (Ali, Parikh, and Shah 1996). Attempting to explain racial/ethnic differences in workers' propensity to cross picket lines during a strike, Gramm and Schnell (1994) find that minority participation in the 1987 National Football League strike depended significantly and positively on the minority status of each team's union representative. Explaining why Turkish immigrants choose to immigrate to Germany, Waldorf, Esparza, and Huff (1990) report a wide variety of motives, many of which are not financial, ranging from perceived lifestyle benefits to the expressed desire to reunite with family members.

Heterogeneity in entrepreneurs' closeness to government is documented in a study of Israeli entrepreneurs (Lerner 1989), which finds that variables such as risk tolerance, interest in foreign trade, and industry type strongly condition the probability of receiving state-subsidized capital. And research on heterogeneous preferences and their connection to labor/leisure choices 
(based on differential desires for income) suggests that these sources of variation are correlated with marital status (Grossbard-Shechtman and Neuman 1988) and with attitudinal measures of "family orientation" (Cappelli, Constantine, and Chadwick 2000). Thus, the marriage premium puzzle may be a consequence of heterogeneous preferences, measures of which are generally absent in wage regressions, which, because they are correlated with marriage, would therefore lead to spurious marriage-on-wage effects.

\section{Social Norms and Trust}

One way to model externalities is to include agent $i$ 's consumption in agent $j$ 's utility function. This is simply a formalization of the idea that people care about the choices of others, which in itself does not imply that they are altruistic or inclined toward reciprocity. A simplification of this approach is to specify preferences that, in addition to one's own consumption, depend on the population's average level of consumption. This framework provides a nice explanation for the existence of the modern welfare state. With a small amount of altruism (reflected by positive utility from increased levels of average consumption) or risk aversion toward aggregate income shocks, Lindbeck (1997) shows that the most preferred tax-transfer policy provides a moderate minimum income guarantee using progressive taxation.

Arguments in favor of other-regarding behavior are by now numerous: a small propensity to cooperate can be an adaptive trait that enhances the fitness of groups competing for resources (Gintis 2000); in a robust class of evolutionary games, reciprocators who punish those deviating from social norms can invade populations of nonreciprocators (Sethi and Somanathan 2001, 2003); honesty, even when dishonesty is feasible, can increase a firm's profitability (Cialdini 
1996); and firms with prosocial corporate cultures save on labor costs when hiring workers with a particular level of human capital (Frank 1996). The welfare-enhancing role of social norms in favor of trust or concern with the least well-off members of the group are documented in smallscale societies (Onyeiwu 1997; Heinrich et al. 2001), informal credit markets (Yotopoulos and Floro 1992), and modern economic environments such as the agribusiness industry (Wilson 2000).

Skeptics worry, however, that social norms favoring in-group cooperation may be too weak to offset individual gains from non-cooperation while, in other settings, excessive in-group cooperation may lead to undesirable forms of discrimination against non-group members. Loewenstein (1996) paints an extremely bleak picture for the possibility of managerial altruism. He points out that the experimental evidence on altruism suggests that such sentiments are typically weak and transient. According to studies he cites, most individuals find it easy to discount negative consequences borne by others, especially when there is no face-to-face interaction with victims. Loewenstein warns that future reputational benefits, which some have suggested might lead to prosocial behavior among firms and managers, tend to be overwhelmed by immediate benefits. He cautions that decision-making biases do not seem to self-correct and that unequal gains are easily rationalized by the recipients of those gains. The potentially discriminatory consequences of favorable in-group sentiment in the labor-market context are illustrated by models of reputational cascades (Kuran 1998), social conventions (Kaneko and Kimura 1992), and the psychology of "inappropriate helpfulness" (Brewer 1996).

\section{Labor Contracts and the Structure of Work}


More than fifty years ago, Simon (1951) posed a fundamental question concerning labor contracts: why is it more common that such contracts stipulate the exchange of wages for time rather than the completion of a particular task? Simon points out that because workers remain interested in how employers use their labor even after work contracts are agreed to, rental contracts offer a better, although still imperfect, analogy for labor than do sales contracts. Simon's analysis demonstrates that uncertainty over which actions will be most effective in accomplishing the employer's objectives makes it desirable for the employer to purchase an option on the employee's time rather than contracting for piecework.

According to Simon's model, workers have ranges of accepted behaviors that can agreeably be asked of them. The more indifferent workers are over the elements within this range, the cheaper workers will sell an option on their time (i.e., the lower the wage). Simon emphasizes that, apart from the domain of negotiable job characteristics, other elements of work remain entirely under the discretion of workers and thus susceptible to varying levels of effort, an idea that overlaps with the ideas of Leibenstein described in an earlier section. A wide range of economic and multidisciplinary research exists analyzing various aspects of labor contracts and the structure of work. The following sections cover areas that stand out in terms of the role that behavioral techniques have played in providing new insights, in the tradition of Simon and beyond.

\section{Absenteeism, Overtime, and the Structure of the Workweek}

Neoclassical analyses suggest that compressing the workweek (e.g., from five eight-hour days to four ten-hour days) should reduce absenteeism and discourage workers from taking too many 
high-wage overtime hours. The four-day 40-hour workweek discourages absenteeism because the cost of missing a day's work is ten hours of lost wage income instead of eight. Overtime is less attractive with the four-day workweek because the marginal disutility of the eleventh and twelfth hours exceeds that of the ninth and tenth hours. Since the psychic cost of overtime is higher, due to both physical and mental exhaustion after ten hours on the job, workers are predicted to choose less of it (Yaniv 1986).

Similar cost savings as well as reductions in transportation congestion costs have been attributed to the idea of flextime (labor contracts that give employees flexibility in setting their own work hours). Although survey evidence suggests that flextime is popular with workers, the empirical evidence on its capacity to provide cost savings is weak (Moss and Curtis 1985). Golden $(1996,1998)$ emphasizes that one must consider flows of potential benefits associated with time on the job that are not included in the standard neoclassical model in order to theoretically model flexibility of hours worked. Golden (2001) reports that access to flexible work hours increased dramatically from the mid-1980s through the early 1990s, with nearly one in three workers reporting some ability to set their own hours in 1997, but that the increasing trend came to a halt, leaving a static, highly nonuniform distribution of access to flexibility across job types and worker ethnicity and gender. Behavioralists working with cultural and attitudinal measures have suggested links between those variables, workplace flexibility, and rates of absenteeism (Kaiser 1998).

\section{Worker Participation and Control}

Worker participation in production decisions and control over hours, wages, and other workplace 
issues typically under the purview of managers and corporate boards brings with it both costs and benefits. Behavioral economics has devoted considerable attention to the question of how those costs and benefits compare and to the normative issue of whether U.S. firms employ an optimal mix of worker versus managerial and board control. Tomer (1988) argues that there exists a maximally X-efficient participative ideal, that is, an organizational scheme for distributing control among workers, owners, and managers. Using this ideal as a benchmark, several behavioral analysts conclude that superior organizational schemes are indeed available and that firms and perhaps governments should actively promote workplace decentralization, promising significant improvements in both profits and workers' well being (Wiendieck 1988).

Case studies illustrate the immense potential for innovative control structures to produce impressive levels of efficiency. Hattwick's (1987) study of the Woodward Governor Company tells the story of how a one-worker/one-vote democratic decision-making procedure helped that company survive the Great Depression. Faced with steep losses, the company asked workers whether they preferred layoffs or hours reductions. Workers negotiated and voted on a deal that offered reduction to half-time hours in exchange for a commitment to avoid layoffs for as long as possible. Managers wound up taking out loans against their personal assets to make good on their commitment to avoid layoffs.

Eventually, Woodward Governor turned profitable again and emerged as a successful Fortune 100 firm. The atmosphere of mutual trust and appreciation that came out of those challenging times persisted for decades, as did the participatory mode of decision making. As the firm grew, decisions such as whether to invest in new production facilities were put to firmwide employee votes. Management voluntarily provided health insurance and paid workers to stay home when ill, which, managers claimed, helped prevent the spread of illness among workers. In 
designing its pension plan, the firm provided identical retirement packages for all employees, from top managers to entry-level employees. The relatively modest pension plan reflected the owners' complex beliefs, which valued self-reliance while rejecting paternalistic or welfare-state managerial models, always placing a high value on equality and participation in the decisionmaking process.

Studies of the grievance process through which workers present their requests to corporate decision makers demonstrate that differences in management styles consistently predict grievance outcomes, with the implication that friendly and participative structures of control are better for all parties involved (Bemmels 1994). Skeptics point out, however, that in spite of the benefits from worker participation and shared control, worker-controlled firms may never be able to compete and gain a foothold in the business world. One important reason for such pessimism is the possibility that, because workers generally lack the political connections (and perhaps managerial expertise) that owners have, worker-controlled firms may face higher borrowing costs. All else equal, unless the benefits of nonstandard control systems offset their elevated costs of investment financing, even X-efficiency-superior control systems, may never get off the ground (Putterman 1992).

\section{Unions}

Walton and McKersie (1991) detail four distinct functions of bargaining in labor negotiations. Zero-sum bargaining over wages and other financial benefits is probably the most obvious function of unions. However, in addition to adversarial, fixed-pie negotiation, bargaining can also serve a so-called integrative function, aimed at increasing mutual benefits and expanding the 
size of the pie. Third, because workers and managers generally care about the worker-manager relationship itself and its impact on quality of life during work hours, so-called attitudinal bargaining serves to expand nonfinancial benefits stemming from on-the-job social interaction. Finally, because there are other stake holders in the outcomes considered in many labor negotiations, bargaining sometimes focuses on the interests of third parties, a function referred to as intraorganizational. Statistical studies of actual negotiations and outcomes tend to support Walton and McKersie's claim that negotiations have both distributive (zero-sum) and integrative components (Peterson and Tracy 1977).

When put to empirical econometric tests, neoclassical theories of strikes have trouble explaining the available data (Freeman 1997). Both theoretical and experimental studies of reciprocity (Fehr, Gachter, and Kirchsteiger 1997) suggest that the integrative aspect of bargaining, missing from many neoclassical analyses, is an important part of why the standard theory on the subject is incomplete.

Among those patterns that have proven difficult to explain are the following. The mere availability of the strike option, restricted by law for some public employees in certain states, appears to raise teacher salaries by as much as 10 percent (Delaney 1983). Also, unionized workers are more likely to have pension benefits than nonunion workers (Gustman and Steinmeier 1986).

Some analysts suggest, however, that the union/nonunion distinction is fuzzy, with many unionlike options, such as slowdowns and sabotage, available to nonunion workers as well (Ulman 1990). In explaining the strengthening and subsequent decline of union strength in the United States, Piore (1995) argues that cultural trends, social forces, and collective emotions are the most important causes. Debate about the functions and consequences of unions is likely to 
continue.

\section{Conclusion}

This survey demonstrates that behavioral labor economics is pursing a path of generalization rather than revolution. In many instances, its methods include or overlap with neoclassical methods that deal with the same problems. Concerning the connection between behavioral methodology and policy, the studies cited here clearly demonstrate that empiricism trumps ideology. Behavioralists show themselves to be empiricists principally, elaborating and testing theory based on assumptions that accord with observation.

Critics sometimes raise the concern that behavioral economics' openness to the possibility of decision-making imperfections also opens the door to theories that favor paternalistic economic policy. However, the existence of policies that lead to improvements over decentralized markets in no way follows from the existence of decision-making imperfections (see Smith 2003). Virtually all the behavioralists whose works are cited above acknowledge this point in some way. Some even suggest that the existence of micro-level imperfections underscores the need for free markets and competition - to effectively aggregate information, make that information public, and coordinate behavior in the absence of centralized control. While some papers reported on here call for policy interventions to help steer the economy along an improved path, this is by no means the general case.

The survey documents an impressive accumulation of contributions to long-standing labor questions such as fluctuations in real wages, hours worked, the participation rate, and the economic impact of labor unions. While these questions will no doubt continue to attract the 
attention of behavioral economics in years to come, five research and data collection priorities stand out: (1) better empirical measures of effort and study designs that make effort easier to observe, (2) survey data sets that include psychometric measures of mental health and attitudinal variables along with traditional labor variables such as earnings, hours, and demographics, (3) macro labor models with preference change that make falsifiable predictions, (4) normative analysis of the potential for efficiency improvements from greater flexibility in the scheduling of work, and (5) anthropological techniques for collecting better descriptive accounts of economic environments and the preferences of labor market participants.

Because behavioral labor is rooted in empiricism, the five priorities listed above concentrate on the development of new measures, the collection of new data, and the construction of theories with explicit empirical implications. Many of the existing behavioral analyses of effort, unemployment, and worker psychology point directly to the need for better data. Better data are also required for behavioral theory to prove its worth in the domain of policy analysis. The existing literature makes definite strides down that path. Improved data with variables designed for testing psychological theories and models of preference change will ultimately help sort out good results from those that turn out merely to be good tries.

\section{References}

Agell, Jonas, and Per Lundborg. 2003. "Survey Evidence on Wage Rigidity and Unemployment: Sweden in the 1990s." Scandinavian Journal of Economics 105: 15-29. Akerlof, George A. 1982. "Labor Contracts as Partial Gift Exchange.” Quarterly Journal of Economics 97: 543-69. 
Akerlof, George A., and Janet L. Yellen. 1990. "The Fair Wage-Effort Hypothesis and Unemployment." Quarterly Journal of Economics 105: 255-83.

Ali, Farman, Ashok Parikh, and Mir Kalan Shah. 1996. "Measurement of Economic Efficiency Using the Behavioral and Stochastic Cost Frontier Approach.” Journal of Policy Modeling 18: 271-87.

Allen, R. Douglas, and Fred L. Fry. 1987. "An Investigation of Sex as a Moderator of the Relationship Between Occupational Stress and Perceived Organizational Effectiveness in Formal Groups.” Journal of Behavioral Economics 16: 9-15.

Altman, Morris. 1992. "The Economics of Exogenous Increases in Wage Rates in a Behavioral/X-Efficiency Model of the Firm.” Review of Social Economy 50: 163-92.

_ 1995. "Labor Market Discrimination, Pay Inequality, and Effort Variability: An

Alternative to the Neoclassical Model.” Eastern Economic Journal 21: 157-69.

-1996. Human Agency and Material Welfare: Revisions in Microeconomics and Their Implications for Public Policy. Boston: Kluwer Academic Publishers.

—. 1999a. "Labour Market and Market Power.” In Phillip O’Hara, ed., Encyclopedia of Political Economy, 643-45. London: Routledge.

—.1999b. "New Estimates of Hours of Work and Real Income from the 1880s to 1930:

Long Run Trends and Workers' Preferences." Review of Income and Wealth 45: 353-72.

—. 2000. "Labor Rights and Labor Power and Welfare Maximization in a Market

Economy: Revising the Conventional Wisdom.” International Journal of Social Economics 27: $1252-69$.

—. 2001a. "A Revisionist View of the Economic Implications of Child Labor Regulations." Forum for Social Economics 30: 1-23. 
_ 2001b. "Preferences and Labor Supply: Casting Some Light into the Black Box of Income-Leisure Choice.” Journal of Socio-Economics 30: 199-219.

_ 2002. "Economic Theory, Public Policy and the Challenge of Innovative Work Practices." Economic and Industrial Democracy: An International Journal 23: 271-90. Altman, Morris, and Louise Lamontagne. 2003. "On the Natural Intelligence of Women in a World of Constrained Choice: How the Feminization of Clerical Work Contributed to Gender Pay Equality in Early Twentieth Century Canada." Journal of Economic Issues 37(4): 1045-1074.

Apps, P.F., and R. Rees. 1996. "Labor Supply, Household Production and Intra-family Welfare Distribution." Journal of Public Economics 60: 199-219.

Barrett, Kevin Stanton, Anya M. McGuirk, and Richard Steinberg. 1997. "Further Evidence on the Dynamic Impact of Taxes on Charitable Giving.” National Tax Journal 50: 321-34.

Baxter, J.L. 1988. Social and Psychological Foundations of Economic Analysis. New York: Simon and Schuster.

Bemmels, Brian. 1994. “The Determinants of Grievance Initiation.” Industrial and Labor Relations Review 47: 285-301.

Berg, Nathan. 2003. "Normative Behavioral Economics." Journal of Socio-Economics 32: 41127.

Berg, Nathan, and Donald Lien. 2003. "Tracking Error Rules and Accumulated Wealth." Applied Mathematical Finance 10, 2: 91-119.

Bewley, Truman. 1999. Why Wages Don't Fall During a Recession. Cambridge: Harvard University Press.

Boddy, Raford, Roger Frantz, and Barbara Poe-Tierney. 1986. "The Marginal Productivity 
Theory: Production Line and Machine Level by Work-Shift and Time of Day." Journal of Behavioral Economics 15:1-23.

Brewer, Marilynn B. 1996. "In-Group Favoritism: The Subtle Side of Intergroup

Discrimination.” In David M. Messick and Anne E. Tenbrunsel, eds., Codes of Conduct: Behavioral Research into Business Ethics, 160-70. New York: Russell Sage Foundation. Camerer, Colin. 1998. "Behavioral Economics and Nonrational Organizational Decision Making.” In Jennifer Halpern and Robert Stern, eds., Debating Rationality: Nonrational Aspects of Organizational Decision Making, 53-77. Ithaca, NY: Cornell University Press.

Camerer, Collin, Linda Babcock, George Loewenstein, and Richard Thaler. 1997. "Labor Supply of New York City Cabdrivers: One Day at a Time." Quarterly Journal of Economics 112: $407-41$.

Cappelli, Peter, Jill Constantine, and Clint Chadwick. 2000. "It Pays to Value Family: Work and Family Tradeoffs Reconsidered.” Industrial Relations 39: 175-98.

Carlin, Paul S. 1989. "Why the Incidence of Shirking Varies Across Employers." Journal of Behavioral Economics 18: 61-73.

Chenu, Alain, and John P. Robinson. 2002. "Synchronicity in the Work Schedules of Working Couples." Monthly Labor Review 125: 55-63.

Cialdini, Robert B. 1996. "Social Influence and the Triple Tumor Structure of Organizational Dishonesty.” In David M. Messick and Anne E. Tenbrunsel, eds., Codes of Conduct: Behavioral Research into Business Ethics, 44-58. New York: Russell Sage Foundation. Darity, William A., and Arthur H. Goldsmith. 1996. "Social Psychology, Unemployment and Macroeconomics." Journal of Economic Perspectives 10: 121-40.

Delaney, John Thomas. 1983. "Strikes, Arbitration, and Teacher Salaries: A Behavioral 
Analysis." Industrial and Labor Relations Review 36: 431-46.

Dickens, William T. 1990. “Assuming the Can Opener: Hedonic Wage Estimates and the Value of Life." Journal of Forensic Economics 3: 51-60.

Di Tommaso, Maria L., and Melvyn Weeks. 2000. "Decision Structures and Discrete Choices: An Application to Labour Market Participation and Fertility." Cambridge Working Papers in Economics 2000-9.

Duesenberry, James S. 1949. Income, Saving and the Theory of Consumer Behavior. Cambridge, MA: Harvard University Press.

Duncan, Alan, and Melvyn Weeks. 1997. "Behavioral Tax Microsimulation with Finite Hours Choices." European Economic Review 41: 619-26.

Dunn, L.F. 1996. "Loss Aversion and Adaptation in the Labor Market: Empirical Indifference Functions and Labor Supply." Review of Economics and Statistics 78: 441-50.

Eckel, Catherine C., and Philip Grossman. 2001. "Chivalry and Solidarity in Ultimatum Games." Economic Inquiry 39: 171-88.

Evangelista, Rinaldo. 1996. “Embodied and Disembodied Innovative Activities: Evidence from the Italian Manufacturing Industry.” In Ernst Helmstadter and Mark Perlman, eds., Behavioral Norms, Technological Progress, and Economic Dynamics: Studies in Schumpeterian Economics, 199-221. Ann Arbor, MI: University of Michigan Press.

Farber, Henry S. 2003. "Is Tomorrow Another Day? The Labor Supply of New York City Cab Drivers.” NBER Working Paper 9706.

Feather, N.T. 1990. The Psychological Impact of Unemployment. New York: Springer-Verlag. Fehr, Ernst, Simon Gachter, and Georg Kirchsteiger. 1997. "Reciprocity as a Contract Enforcement Device: Experimental Evidence.” Econometrica 65: 833-60. 
Fehr, Ernst, and Lorenz Goette. 2002. "Do Workers Work More if Wages Are High? Evidence from a Randomized Field Experiment.” Institute for Empirical Research in Economics Working Paper 125.

Filer, Randall K. 1986. "People and Productivity: Effort Supply as Viewed by Economists and Psychologists.” In Benjamin Gilad and Stanley Kaish, eds., Handbook of Behavioral Economics, A:261-88. Greenwich, CT: JAI Press. 1987. "Joint Estimates of the Supply of Labor Hours and the Intensity of Work Effort." Journal of Behavioral Economics 16: 1-12.

Frank, Robert. 1987. Choosing the Right Pond: Human Behavior and the Quest for Status. New York: Oxford University Press.

— 1996. "Can Socially Responsible Firms Survive in a Competitive Environment?" In David M. Messick and Anne E. Tenbrunsel, eds., Codes of Conduct: Behavioral Research into Business Ethics, 86-103. New York: Russell Sage Foundation.

Frantz, Roger S. 1986. "X-Efficiency in Behavioral Economics.” In Benjamin Gilad and Stanley Kaish, eds., Handbook of Behavioral Economics, A:307-23. Greenwich, CT: JAI Press.

Frantz, Roger S., and Lou Green. 1982. "Prejudice, Mistrust and Labor Effort: Social Influences on Productivity." Journal of Behavioral Economics 11: 101-31.

Freeman, Richard B. 1997. "In Honor of David Card: Winner of the John Bates Clark Medal." Journal of Economic Perspectives 11: 161-78.

Gilad, Benjamin, and Stanley Kaish, eds. 1986. Handbook of Behavioral Economics. Greenwich, CT: JAI Press.

Gilad, Benjamin, Stanley Kaish, and Joshua Ronen. 1988. “The Entrepreneurial Way with Information.” In Shlomo Maital, ed., Applied Behavioral Economics, 2:480-503. New 
York: New York University Press.

Gintis, Herbert. 2000. Game Theory Evolving: A Problem-Centered Introduction to Modeling Strategic Interaction Princeton, NJ: Princeton University Press.

Golden, Lonnie. 1996. "The Economics of Worktime Length, Adjustment and Flexibility:

Contributions of Three Competing Paradigms." Review of Social Economy 54: 1-44.

— 1998. "Working Time and the Impact of Policy Institutions: Reforming the Overtime

Hours Law and Regulation.” Review of Social Economy 56: 525-44.

—. 2001. "Which Workers Get Flexible Work Schedules?" American Behavioral Scientist 44: $1157-78$.

Goldsmith, Arthur H., and William Darity. 1992. "Social Psychology, Unemployment Exposure and Equilibrium Unemployment.” Journal of Economic Psychology 13: 449-71.

Gramm, Cynthia L., and John F. Schnell. 1994. "Difficult Choices: Crossing the Picket Line During the 1987 National Football League Strike." Journal of Labor Economics 12: 41-73.

Grossbard-Shechtman, Shoshana Amyra. 1986. "Marriage and Productivity: An Interdisciplinary Analysis." In Benjamin Gilad and Stanley Kaish, eds., Handbook of Behavioral Economics, A:289-302. Greenwich, CT: JAI Press.

—. 1988. "Virtue, Work and Marriage.” In Shlomo Maital, ed., Applied Behavioral Economics, 1:199-211. New York: New York University Press.

Grossbard-Shechtman, Shoshana Amyra, and Shoshana Neuman. 1988. “Women's Labor Supply and Marital Choice." Journal of Political Economy 96: 1294-302.

Gustman, Alan L., and Thomas L. Steinmeier. 1986. "Pensions, Unions and Implicit Contracts." Working Paper 2036, National Bureau of Economic Research, Cambridge, MA. Hanushek, Eric A. 1986. "Nonlabor Supply Responses to the Income Maintenance 
Experiments." In Alicia H. Munnell, ed., Lessons from the Income Maintenance Experiments: Proceedings of a Conference Held at Melvin Village, New Hampshire, 10621. Boston, MA: Federal Reserve Bank of Boston.

Hattwick, Richard E. 1987. "Democratizing the Workplace: The Case of Irl C. Martin and the Woodward Governor Company." Journal of Behavioral Economics 16: 69-77.

Hausman, Jerry A., and James M. Poterba. 1987. "Household Behavior and the Tax Reform Act of 1986." Journal of Economic Perspectives 1: 101-19.

Helmstadter, Ernst, and Mark Perlman, eds. 1996. Behavioral Norms, Technological Progress, and Economic Dynamics: Studies in Schumpeterian Economics. Ann Arbor: University of Michigan Press.

Henrich, J., R. Boyd, S. Bowles, C. Camerer, E. Fehr, H. Gintis, and R. McElreath. 2001. "In Search of Homo Economicus: Behavioral Experiments in 15 Small-Scale Societies.” American Economic Review Papers and Proceedings 91: 73-78.

Ireland, Thomas R. 1989. "How Shirking Can Help Productivity: A Critique of Carlin and the ‘Shirking as Harm’ Theory.” Journal of Behavioral Economics 18: 75-79.

Kagel, John H., Raymond C. Battalio, and Leonard Green. 1995. Economic Choice Theory: An Experimental Analysis of Animal Behavior. Cambridge: Cambridge University Press.

Kahn, Matthew E. 1998. "Health and Labor Market Performance: The Case of Diabetes." Journal of Labor Economics 16: 878-99.

Kaiser, Carl P. 1998. "Dimensions of Culture, Distributive Principles, and Decommodification: Implications for Employee Absence Behavior.” Journal of Socio-Economics 27, 5: 551-64.

Kaneko, M., and T. Kimura. 1992. "Conventions, Social Prejudices and Discrimination: A Festival Game with Merrymakers." Games and Economic Behavior 4: 511-27. 
Kantarelis, Demetri. Forthcoming. "Occupational Stress: Some Microeconomic Issues."

International Journal of Management Concepts and Philosophy.

Kaufman, Bruce E. 1989. "Models of Man in Industrial Relations Research." Industrial and Labor Relations Review 43: 72-88.

—. 1999. "Expanding the Behavioral Foundations of Labor Economics." Industrial and Labor Relations Review 52: 361-92.

Korpi, Tomas. 1997. "Is Utility Related to Employment Status? Employment, Unemployment, Labor Market Policies and Subjective Well-Being Among Swedish Youth.” Labour Economics 4: 125-47.

Krueger, Alan. 2003. "Why Tax Cuts Will Not Pay Off." New York Times, June 26.

Kuran, Timur. 1998. "Ethnic Norms and Their Transformation Through Reputational Cascades." Journal of Legal Studies 27: 623-59.

Langowitz, Nan S. 1991. "Motivations for Innovation in Firms: Economic Insight into the U.S.

Competitive Stance." Journal of Socio-Economics 20: 251-62.

Lazear, Edward. 1995. Personnel Economics. Cambridge: MIT Press.

Leibenstein, Harvey. 1986. "Intra-firm Effort Decisions and Sanctions: Hierarchy Versus Peers." In Benjamin Gilad and Stanley Kaish, eds., Handbook of Behavioral Economics, A:21331. Greenwich, CT: JAI Press.

Lerner, Miri. 1989. "Paternalism and Entrepreneurship: The Emergence of State-Made Entrepreneurs.” Journal of Behavioral Economics 18: 149-66.

Lewin, David, and George Strauss. 1988. "Behavioral Research in Industrial Relations: Introduction." Industrial Relations 27: 1-6.

Lindbeck, Assar. 1997. "Incentives and Social Norms in Household Behavior." American 
Economic Review 87: 370-77.

Loewenstein, George. 1996. "Behavioral Decision Theory and Business Ethics: Skewed Tradeoffs Between Self and Other.” In David M. Messick and Anne E. Tenbrunsel, eds., Codes of Conduct: Behavioral Research into Business Ethics, 214-27. New York: Russell Sage Foundation.

Maital, Shlomo, ed. 1988. Applied Behavioral Economics. 2 vols. New York: New York University Press.

Martin, Linda R., and Sandra Morgan. 1995. "Middle Managers in Banking: An Investigation of Gender Differences in Behavior, Demographics, and Productivity.” Quarterly Journal of Business and Economics 34: 55-68.

Moss, Richard Loring, and Thomas D. Curtis. 1985. "The Economics of Flextime.” Journal of Behavioral Economics 14: 95-114.

Norsworthy, J.R., and Craig A. Zabala. 1990. "Worker Attitudes and the Cost of Production: Hypothesis Tests in an Equilibrium Model.” Economic Inquiry 28: 57-78.

O’Higgins, Eleanor R.E. 1988. “Innovation, Entrepreneurship, Efficiency and Strategy-Manager Fit in Irish Agricultural Cooperatives.” In Shlomo Maital, ed., Applied Behavioral Economics, 2:458-79. New York: New York University Press.

Onyeiwu, Steve. 1997. "Altruism and Economic Development: The Case of the Igbo of Southeastern Nigeria." Journal of Socio-Economics 26, 4: 407-20.

Peterson, Richard B., and Lane Tracy. 1977. "Testing a Behavioral Theory Model of Labor Negotiations." Industrial Relations 16: 35-50.

Phipps, Shelley A., and Peter S. Burton. 1995. "Social/Institutional Variables and Behavior Within Households: An Empirical Test Using the Luxembourg Income Study.” Feminist 
Economics 1: 151-74.

Pieters, Rik G.M., and Bas Verplanken. 1988. "The Joy of Thinking about Nuclear Energy." In Shlomo Maital, ed., Applied Behavioral Economics, 2:537-49. New York: New York University Press.

Piore, Michael. 1995. Beyond Individualism. Cambridge: Harvard University Press.

Putterman, Louis. 1982. "Some Behavioral Perspectives on the Dominance of Hierarchical over Democratic Forms of Enterprise." Journal of Economic Behavior and Organization 3: 139-60.

Reber, Robert A., Jerry A. Wallen, and Jagdeep S. Chhokar. 1984. "Reducing Industrial Accidents: A Behavioral Experiment.” Industrial Relations 23: 119-25.

Romme, A. Georges L. 1990. "Projecting Female Labor Supply: The Relevance of Social Norm Change." Journal of Economic Psychology 11: 85-99.

Saez, Emmanuel. 2002. “Optimal Income Transfer Programs: Intensive Versus Extensive Labor Supply Responses.” Quarterly Journal of Economics 117: 1039-73.

Schechter, Mordecai. 1988. "Incorporating Anxiety Induced By Environmental Episodes In Life Valuation.” In Shlomo Maital, ed., Applied Behavioral Economics, 1:529-536. New York: New York University Press.

Schwartz, Hugh. 1987. "Perception, Judgment, and Motivation in Manufacturing Enterprises: Findings and Preliminary Hypotheses from In-Depth Interviews.” Journal of Economic Behavior and Organization 8: 543-65.

—. 2002. "Herbert Simon and Behavioral Economics." Journal of Socio-Economics 31, 3: $181-89$.

Sethi, Rajiv, and E. Somanathan. 2001. "Preference Evolution and Reciprocity.” Journal of 
Economic Theory 97, 2: 273-97.

—. 2003. "Understanding Reciprocity." Journal of Economic Behavior and Organization 50, 1: 1-27.

Shapiro, Carl, and Joseph E. Stiglitz. 1984. "Equilibrium Unemployment as a Worker Discipline Device." American Economic Review 74: 433-44.

Sharir, Shmuel. 1976. "Work Choices Under an Earnings Target: The Case of Multiple Jobholding." Journal of Behavioral Economics 5: 93-118.

Shen, T.Y. 1996. "Schumpeterian Competition and Social Welfare." In Ernst Helmstadter and Mark Perlman, eds., Behavioral Norms, Technological Progress, and Economic Dynamics: Studies in Schumpeterian Economics, 51-70. Ann Arbor, MI: University of Michigan Press.

Simon, Herbert A. 1951. "A Formal Theory of the Employment Relationship." Econometrica 19: 293-305.

Smith, Vernon L. 2003. "Constructivist and Ecological Rationality in Economics." American Economic Review 93: 465-508.

Sorensen, James E. 1990. “The Behavioral Study of Accountants: A New School of Behavioral Research in Accounting." Managerial and Decision Economics 11: 327-41.

Stiglitz, Joseph. 1988. “Economic Organization, Information, and Development.” In H. Chenery and T.N. Srinivasan, eds., Handbook of Development Economics, 94-160. New York: Elsevier.

Tiemann, Thomas K., and Peter A. Veglahn. 1979. "Market Concentration: The Relationship to Job Satisfaction." Journal of Behavioral Economics 8: 137-50.

Tomer, John. 1986. "Productivity and Organizational Behavior: Where Human Capital Theory 
Fails.” In Benjamin Gilad and Stanley Kaish, eds., Handbook of Behavioral Economics, A:233-55. Greenwich, CT: JAI Press.

—. 1988. "Worker Participation: Paths to Higher Productivity and Well-Being.” In Shlomo Maital, ed., Applied Behavioral Economics, 2:637-49. New York: New York University Press.

Ulman, Lloyd. 1990. "Labor Market Analysis and Concerted Behavior.” Industrial Relations 29: 281-99.

Veblen, Thorstein. 1899. The Theory of the Leisure Class. New York: Macmillan.

Waldorf, B.S., A. Esparza, and J.O. Huff. 1990. “A Behavioral Model of International Labor and Nonlabor Migration: The Case of Turkish Movements to West Germany, 1960-1986.” Environment and Planning A 22: 961-73.

Walton, Richard E., and Robert B. McKersie. 1991. A Behavioral Theory of Labor Negotiations: An Analysis of A Social Interaction System. 2nd ed. Ithaca, NY: ILR Press.

Westman, Mina, and Amiram Gafni. 1988. "Hypertension Labeling as a Stressful Event Leading to an Increase in Absenteeism: A Possible Explanation for an Empirically Measured Phenomenon.” In Shlomo Maital, ed., Applied Behavioral Economics, 2:507-27. New York: New York University Press.

Wiendieck, Gerd. 1988. "Quality Circles and Corporate Identity_Towards Overcoming the Crisis of Taylorism.” In Shlomo Maital, ed., Applied Behavioral Economics, 2:620-36. New York: New York University Press.

Wiesenfeld, Batia, and Joel Brockner. 1998. “Toward a Psychology of Contingent Work.” In Jennifer Halpern and Robert Stern, eds., Debating Rationality: Nonrational Aspects of Organizational Decision Making, 195-215. Ithaca, NY: Cornell University Press. 
Wilson, Paul N. 2000. "Social Capital, Trust, and the Agribusiness of Economics." Journal of Agricultural and Resource Economics 25: 1-13.

Yaniv, Gideon. 1986. "Absenteeism, Overtime, and the Compressed Workweek." Journal of Behavioral Economics 15: 211-19.

Yotopoulos, Pan A., and Sagrario L. Floro. 1992. "Income Distribution, Transaction Costs and Market Fragmentation in Informal Credit Markets.” Cambridge Journal of Economics 16: $303-26$. 